It is possible that others of the smaller species of Paramys would prove to belong to this genus, if better known. P. copei Loomis of the Wind River (Plesiarctomys delicatissimus of Cope) certainly does not.

The relations of this genus are clearly with Paramys and not with Mysops or Sciuravus, but it presents an interesting new variant on the very limited range of structural divergencefound among Eocene rodents.

The characters of the infraorbital region are as in Paramys, except that the muscle scar on the inferior surface of the root of the zygoma is less sharply marked off from the anterior surface, which is pitched so as to face more downward, and lacks the pit that in $P$. delicatus intervenes between the infra-orbital foramen and the first upper premolar p. ${ }^{3}$ The latter tooth is also smaller than in $P$. delicatus. These are individually variable characters in $P$. delicatus, and are not of generic importance.

\title{
SOME CALIFORNIAN EXPERIENCES WITH BAT ROOSTS
}

\section{By A. Brazier Howell}

[Plate 9]

To those who have investigated bats and their habits to even a slight extent, these mammals are of particular interest. From earliest times they have been so little known and understood that they have been regarded with greatest superstition. They hunt during the hours of darkness, spend the day in hiding in out-of-the-way places, and are altogether such retiring, elusive little beasts, that the mammalogist who would become better acquainted with them must be continually on the alert. While riding about the country, one should keep an eye subconsciously active to remark favorable locations, such as large attics with slatted ventilators. If a colony has taken possession of the space between the walls of a house or cornice, there will often be a telltale smudge made by the rubbing of small bodies as they emerge from hiding. While fortified with a pocket full of cigars, a collector, by judicious questioning of village constables, blacksmiths, and such public characters will often meet with success; and I have obtained excellent results from advertising in farm papers.

Our bats may be placed for convenience in two arbitrary groupsthose which roost singly or a very few together in trees, high cliffs, or similar locations; and those which are in the habit of gathering in 
numbers in caves, hollow trees, and old buildings. In the case of the former class, few of us are qualified to talk at great length. Our experiences are limited to a Myotis darting from a hole in a stub, a Pipistrellus slipping at dusk from a cranny high on a cliff, or perhaps a Nycteris hanging motionless in a fruit tree. The expert collector can identify the majority of his chiroptine acquaintances on the wing, but this knowledge cannot be transferred to print, and the opportunities for further enlightenment are so few that only an observer of long experience is qualified to add much of value to the life-histories of the more solitary bats. Even in the case of those species with which I am most familiar, there has been so little complementary work done by others that many of my deductions and theories may have to be revised at a later date. Some of them are here offered tentatively, in the hope that others will be encouraged to delve deeper, as their opportunities permit, into this fascinating branch of investigation.

Most of the better known species of European bats are non-migratory and spend the winters in more or less complete dormancy. In fact, I believe that direct evidence in favor of migration has been obtained in the case of only a very few European forms, and continental naturalists received with considerable surprise the evidence that certain of our boreal species do perform extensive migrations. However, American students have been rather slow to follow this lead, and seem loath to believe that except in southern districts, most of our forms are migratory. Why not? A few have been reported in hibernation, but these reports are very rare and it is more logical to suppose that the majority migrate. I am not prepared to state that none of our California bats hibernate; and, conversely, that as a rule, all migrate; but I do believe that all except the mastiff (Eumops) are migratory to some extent, and that species may retire from the more northern boundaries of its range during the coldest weather. Most of our summer bat population is absent during the winter and its place is then taken by forms from farther north or from higher altitudes.

With us, it is the rule that all early flying bats are of the small-eared species, while the large-eared ones, unless some special method of feeding brings them out, fly later. The exception is Antrozous, which is often awing ten minutes before it is too dark to shoot; but this bat feeds extensively upon the flightless Jerusalem cricket (Stenopelmatus), where these occur and the large ears probably enable it to catch the faint sounds made by the crawling insects. In California, Eptesicus is a very early flier, while in the East it appears at late twilight; so the 
time of daily appearance evidently varies considerably in different parts of the range of the species.

Several foreign observers have conducted exhaustive experimentstoo well known to dwell upon here at much length-which prove that all bats are provided with highly developed tactile nerves in the wing membrane; but that those with very large ears, in addition to face and nose appendages, have these members so extremely sensitive that it is beyond human comprehension. They can dodge threads hung in a dark room and perform other remarkable feats. It is small wonder that these peculiarly endowed creatures should select the darkest hours in which to do their hunting, while their less gifted brethren often appear at sunset. Certain students have claimed that the sense of sight in the large-eared bats is less acute than in those with small ears, and this may usually be so, but certainly not in the case of Macrotus, which can see better than any other bats with which I am acquainted. In some genera, the formation of the nose bones indicates an especially keen sense of smell, and such probably often pick insects from leaves and other resting places (as Plecotus is known to do).

Many bats have the power partially to suspend animation when asleep. They then become semi-torpid, with decreased temperature and respiration, even on the hottest days; and it takes several moments -longer in cold weather-for them fully to regain their normal activity. This torpidity evidently can be indulged in by the bats at will, and during cooler weather may last for considerable periods. Rain, unless accompanied by very low temperature, has little effect upon bats, but high winds render them almost helpless, and the partial suspension of all bodily functions then stands them in good stead and enables them to bide their time with considerable comfort until the climatic conditions are more propitious. This phenomenon I have called voluntary hibernation, as opposed to the true hibernation in which, because of cold, failure of food supply, or other external influences, an animal becomes completely torpid in spite of itself. The so-called hibernation of most bats evidently belongs to the former class, although there are at least several foreign species which hibernate in the true sense of the word.

Among most forms of bats, the sexes are usually found apart, especially at the season when the young are born. Of the species most typical of the deserts, the males probably spend the entire season in the one zone; but with certain others, as G. M. Allen has pointed out, the males may seek a higher altitude than do the females during the hottest weather. Certain collectors have noted that only females and 
young were found in the breeding area, while the males had sought a higher zone.

If a colony of bats is located in an attic, the spots which to us appear most favorable are often unoccupied. When a particular site is once chosen, a little use will fix the bat scent and it will always be selected thereafter. The surface against which the little bodies rest becomes smooth and oily, and often there will be deposits of urine salts a half inch thick. Ectoparasites usually abound, but, as far as I am aware, they are of species which cannot survive upon human hosts. An abandoned roost is rare and it is almost impossible to drive the tenants from a favorite home. Only the most persistent persecution and repeated raids will have any effect, and even if the whole colony is annihilated others will often take possession the following year. A colony of bats is a decided asset, especially in a district where there are many mosquitoes, and it should be broken up only when the annoyance from its presence becomes very great.

The California leaf-nose (Macrotus californicus) is a common desert bat and is found only in caves and old mines. Probably it would be nearly as common in the San Diegan coast region if natural caves were not so scarce. The Salton Sea section is an especially fine locality for it, for here there are many caves which the long-departed waves at sea level have tunnelled out of the rocky coast line. Most of these caves are rather shallow and nearly all are tenanted by colonies of this bat-from a score to two-hundred individuals to a colony. They hang singly from the roof by their long legs and are very alert to escape an approaching danger. When one is within thirty feet of them away they go, circling about and dashing out from the entrance to the cave. If one remains quiet a few will return and hang to a horizontal surface, gently fanning half-closed wings and twisting about on one leg with their heads turning in every direction to watch for danger. When alighting they do not catch hold by the thumbs and then turn about head downwards, but "flip up" just as they alight and hang directly by their feet. It is significant that these bats have very long legs, and that the long-legged European Rhinolophus also uses this method of alighting. This habit is doubtless a necessity to species that hang directly from a horizontal surface, and this method of roosting probably tends to lengthen the legs. It is perhaps a rule that bats with exceptionally long legs are free hangers; or, in other words, that they hang by the feet without support from any other part of the body. 
Although the leaf-nose is a very late flier and I have never heard of it being observed hunting before complete darkness sets in, we found the wings of several diurnal butterflies, as well as parts of moths, beneath their roosts. The sexes have been found together only during the mating season. It is not a species that is strictly migratory, and may not be so at all, for a colony will spend the winter-apparently in a perfectly active state - in a deep cave, the temperature of which never varies greatly. Shallow caves are, however, deserted at the approach of cold weather; and, judging by the seemingly reduced winter population, it is possible that some of the bats at this season may seek a warmer climate.

Some six hundred Yuma bats (Myotis yumanensis yumanensis) were found at the one and two-hundred foot levels of the old Senator Mine on the Colorado River. Nearer the surface many were clinging singly to the walls, and these were in a sound sleep, squirming but feebly when plucked off like ripe fruit. Nearby there were a few lively ones, and those in bunches at the deeper levels were all active. The latter were gathered in two knots of a hundred each and one lot of over three hundred, in a compact mass, on the uneven roof of a chamber. When these were approached too closely, the bats swarmed off in every direction, bumping into and crawling all over us. The species is a very late flier and I have never seen it awing before dark.

There is a colony of Tejon bats (Myotis yumanensis sociabilis) in an old adobe store-house at Fort Tejon, Kern County. A new galvanized iron roof was put on this building some years since and the bats are now distributed in the cracks along the peak. On September 3 there were at least a thousand of them present and I swept many of them into a sack with my bare hands as they congregated in clusters against the angles of the rafters. They were quick to slip into cracks, and when poked at they catapulted forth, and, as often as not, flew directly in my face. On September 23 there were only two hundred left, and by December 16 all had departed. No adult males were secured in this colony. Beyond doubt this form is entirely migratory.

With us, the large brown bat (Eptesicus fuscus fuscus) is the commonest of the early fliers during spring and fall, but during the winter it is either absent or very rare. I suspect that this species is rare on the floor of the valley in midsummer as well, but I am usually away at that season. Their abundance may be more apparent than real, as they put in an appearance early and are such big, conspicuous fellows, they seem to be everywhere. I have first noted them on warm eve- 
nings in late March, and they disappear about the time of the first very cool nights in the fall — when Nycteris may first be expected. Their flight is rather high, steady, and unmistakable; and they are easily shot. In buildings, during the spring, I have found a number of colonies composed of from a dozen to sixty individuals. They are fond of congregating in a narrow space with Nyctinomus but are apt to be found singly in almost any good situation. While examining a deserted building, if one finds a little pile of guano beneath a cranny that is just large enough for a single bat, a likely guess is that he has found the temporary home of an Eptesicus. If one waits about such a place until a few minutes after sunset, he may see several bats leave their retreats, one after the other, and fly off in a rising slant with head well elevated as is a poorwill's after drinking. Each female gives birth to a single young during the last few days of May or the first of June.

The pale lump-nose (Corynorhinus rafinesquii pallescens) is not as common on the deserts as is the leaf-nose, and I have encountered it but once. This was in the old Senator Mine, where we found about a hundred females, each with a naked young from a few days old to a quarter grown, clinging to the roof of a gallery at the two-hundredfoot level. They were in close formation but not touching one another, and, although not as wild as Macrotus, they were quite ready to fly. The only way in which we could capture them was wildly to grab at a bunch with both hands. In another part of the mine we found two single males in a semi-torpid condition, although the surrounding temperature was close to par. These bats appear to be larger than they really are because of their huge ears, to the formation of which and to the fact that they are folded away at times, other writers have called attention. This habit of folding the ears is indulged in whenever the animal is at rest and when no danger threatens. It is not limited to this genus, for Plecotus (a European genus) shares the peculiarity. When the bat is on the alert the ears are held well forward and almost parallel, but when all is quiet they are swung around to the side, either in unison or separately. Then they are "crinkled" along the outer or posterior edge until this forms into tiny accordeon plaits, and the extremities are tucked safely beneath the forearms. When the animal is disturbed the ears may be partly unfurled at once, but all the motions of this operation are slow-at about the rate of a snail's pace.

During the first really warm weather in early April, pallid bats (Antrozous pallidus pacificus) appear in numbers in the orange groves. Stationed in a suitable spot, one is pretty sure to see them at mid- 
dusk. Their large ears give them an odd appearance and their squarish forms are not to be mistaken. They often either alight on the ground or hover just above it with imperceptibly vibrating wings; usually a sign that a Jerusalem cricket has been captured. Such bulky prey is carried to a favorite station, which is generally located in an old shed or loft, but never in the same building as the day roost. Beneath these spots may be found the heads and legs of hundreds of crickets, besides the remains of a very few other insects. I have stunned the bats with blows from a board as they were entering a building with crickets in their mouths, and shot them by the light of a pocket flash as they hung from the ridge and fed. They are decidedly common in the thermal belt and occur in old buildings where a dozen or a hundred pass the days together, but invariably out of sight. Hollow partitions, or deep cracks, where they can hide in comparative safety, are necessary to their comfort, and they strongly resist any efforts to dislodge them from such retreats. When aroused, however, they are not averse to scrambling forth with such agility that it is almost impossible to catch them as they emerge. On May 11, I obtained females which contained two large embryos each.

In another paper (Journal of Mammalogy, vol. 1, no. 3, p. 111) I have discussed Eumops, and this I believe to be the only sedentary, strictly non-migratory bat in the southwestern part of the state. On the lower deserts Antrozous and Corynorhinus may linger through the winter, but on this point I am entirely unqualified to speak. Macrotus, as already mentioned, is considered only partly resident; and although some may consider that the Mexican free-tail (Nyctinomus mexicanus) spends its whole life in one locality, I believe that there is a seasonal shifting, and that further study will show that Nyctinomus is absent from the northern parts of its range during the coldest weather. Our colonies at any rate either dwindle or disappear during the winter, and I judge that most of those free-tails which spend the summer with us go south at the approach of cold weather, and that their places are taken to some extent by individuals from farther north.

The free-tail is our most ubiquitous bat. Not only are its colonies the most numerous but the most populous, and in northern Mexico hundreds of thousands may occur together. Just so it has any sort of cranny into which it can squeeze, it is happy, regardless of whether the site is vacant or occupied by other species. In fact, it shows considerable partiality for the company of Eptesicus and Antrozous. They may be crowded into the corner of an attic, or behind a wooden sign on a 
building, where one would lay odds that they would be cooked to a crisp by the mid-day sun, but at late dusk out they swarm through a hole that seems too small for a shrew to pass, and away into the gathering darkness. When flying, their long, pointed wings are diagnostic, and one soon learns to recognize them. I have watched them at play above a pool when almost too dark to distinguish their forms, and at a time of year when their antics could not be interpreted as a form of courtship. As I sat facing the pale, western sky, one would approach swiftly - they are speedy fliers - give chase to another, and both would do a nose-dive to the surface of the water and rise up to the original height without lessening speed. Sometimes one would tire of the sport while the other continued alone; or half a dozen would join the game, diving from as many directions.

If there is not a crack for them to back into when disturbed they are quite ready to fly, or to flutter to the floor and scurry to shelter with almost the agility and speed of a mouse. When thus "running" their folded wings are kicked up in the rear, giving to their gait a ludicrous, hand-over-hand appearance. When alighting the movements are so quick that the animals appear literally to dive into a hole; and when no hole is available, they will catch on to a support by the thumbs and quickly shift head downwards. This is the normal method of alighting used by bats.

\section{A LIST OF THE COLONIES VISITED}

.1. An abandoned mine two miles north of Potholes, Imperial County, consisting of a very extensive series of connecting chambers. One or two hundred leaf-noses, evidently all males, and a single Yuma bat, May 14. Visited with L. Little.

2. Old Senator Mine, 6 miles north of Potholes, Imperial County. On the one and two hundred foot levels were a colony of a hundred female lump-noses with small young, and some six hundred Yuma bats, mostly females-one of which contained an embryo May 14, 1918. On April 13, 1916, D. R. Dickey found only a dozen lump-noses here in addition to the yuma bats, and by May 10 the former had disappeared and their places been taken by seventy-five leafnoses. Visited with L. Little.

3. A series of old tidal caves at the base of the hills southwest of Thermal, Riverside County. No bats present January 26, but these caves are famous for their summer colonies of leaf-noses and both J. Grinnell and D. R. Dickey have secured bats from the caves in this series.

4. Extensive cave in the hills two miles north of Owensmouth, Los Angeles County, holding 6 leaf-noses April 6, none June 4, and about 30 December 14. There had been many cold nights prior to the last date and, as the end of the 


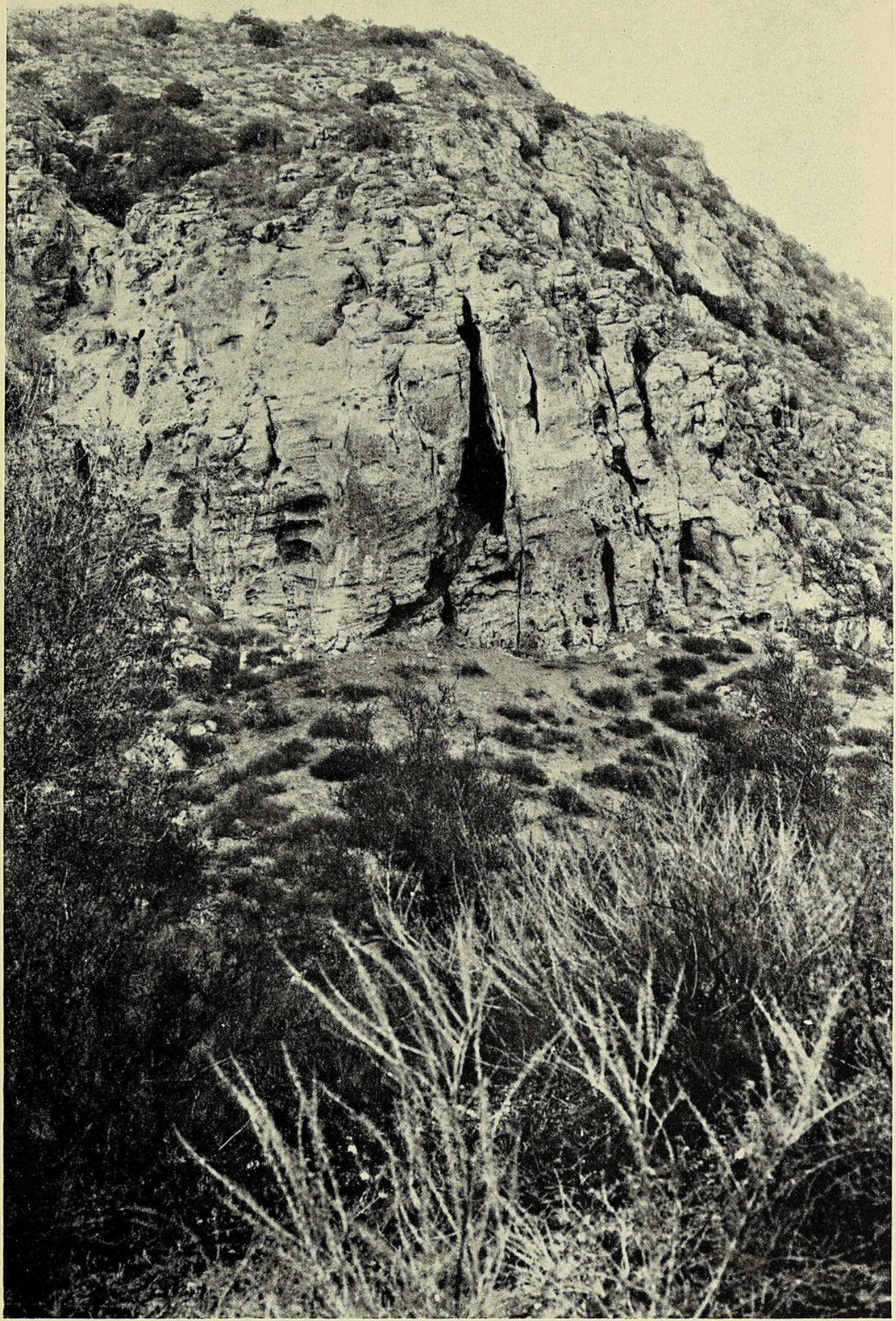

Large Cave near Owensmouth, Los Angeles County, in Which There is a Colony of Leaf-nosed Bats 


\section{$2 \mathrm{BHL}$ Biodiversity Heritage Library}

Howell, A. Brazier. 1920. "Some Californian Experiences with Bat Roosts." Journal of mammalogy 1, 169-177. https://doi.org/10.2307/1373308.

View This Item Online: https://www.biodiversitylibrary.org/item/220052

DOI: https://doi.org/10.2307/1373308

Permalink: https://www.biodiversitylibrary.org/partpdf/90511

\section{Holding Institution}

Smithsonian Libraries

\section{Sponsored by}

Biodiversity Heritage Library

\section{Copyright \& Reuse}

Copyright Status: Not in copyright. The BHL knows of no copyright restrictions on this item.

This document was created from content at the Biodiversity Heritage Library, the world's largest open access digital library for biodiversity literature and archives. Visit BHL at https://www.biodiversitylibrary.org. 